\title{
ENERGY EFFICIENCY DESIGN INDEX OF CONTAINER VESSEL - OPERATIONAL APPROACH
}

\author{
Tadeusz Borkowski, Lech Kasyk, Przemysław Kowalak \\ Maritime University of Szczecin \\ Waly Chrobrego Street 1-2, 70-500 Szczecin, Poland \\ tel.: +48914809400, fax: 48914809575 \\ e-mail:t.borkowski@am.szczecin.pl,l.kasyk@am.szczecin.pl,p.kowalak@am.szczecin.pl
}

\begin{abstract}
The ship "Energy Efficiency Design Index (EEDI)" has been formulated by the IMO Marine Environment Protection Committee (MEPC) as a measure of the $\mathrm{CO}_{2}$ emission performance of ships. The ship EEDI is calculated based on characteristics of the ship at build, incorporating parameters including ship capacity, engine power and fuel consumption. Shipping is responsible for $\mathrm{CO}_{2}$ discharge of approximately 3.3\% global emission and despite being an energy-efficient transport means, compared with other transport modes, there are opportunities for increasing energy efficiency. The EEDI requires a minimum energy efficiency level ( $\mathrm{CO}_{2}$ emissions) per capacity mile (e.g. tonne mile) for different ship type and size sectors. With the level being tightened over time, the EEDI will stimulate continued technical development of all the components influencing the energy efficiency of a ship. The paper presents an overview of EEDI calculation method for container vessels and results of experimental approach. The experimental process results through comprehensive analysis of operational data, from modern container vessel, equipped with direct main propulsion unit have been introduced. Ship operators have already been implementing energy efficiency operational measures and set goals for reducing the energy consumption of their fleet. Performance and savings are not always monitored and reported. However, it can be foreseen that such activity when is successfully promoted, reduction of $\mathrm{CO}_{2}$ emissions can be achieved.
\end{abstract}

Keywords: ship, main propulsion, marine diesel engine, energy efficiency design index, exhaust emission

\section{Introduction}

The ship "Energy Efficiency Design Index (EEDI)" has been formulated by the IMO Marine Environment Protection Committee (MEPC) as a measure of the $\mathrm{CO}_{2}$ emission performance of ships. The EEDI requires a specified energy efficiency that could be primarily, expressed by fuel consumption per capacity mile (e.g. tonne mile) for different ship type types and size. With the level being tightened over time, the EEDI will stimulate continued technical development of all the components influencing the energy efficiency of a ship. Reduction factors are set until 2025 when a 30\% reduction is mandated over the average efficiency for ships built between 1999 and 2009.

The EEDI has been developed for the largest and most energy intensive segments of the world merchant fleet and will embrace about $70 \%$ of emissions from new oil and gas tankers, bulk carriers, general cargo, refrigerated cargo and container ships as well as combination carriers (wet/dry bulk) - see Fig. 1 [2].

There have been challenges with the EEDI baseline approach ship categories, most notably regarding Ro-Ro and RO-Pax cargo vessels and passenger ships. The problems are mainly due to the fact that the aforementioned ship types are typically designed to specific routes and to detailed transport tasks with tight timetables. Overall, high scatter in the ship design and operation speeds exists, leading to a wide variation in propulsion power requirements and machinery configurations of the vessels. The current status of EEDI for Ro-Ro and Ro-Pax vessels is "under development" and mentioned ships are excluded from the EEDI requirement [3].

The particular ship EEDI factor is calculated on characteristics of the ship at build, incorporating parameters including ship capacity, engine power and fuel consumption. The intended application 
of this index was to stimulate innovation and technical development of all elements influencing the energy efficiency of a ship from its design phase.

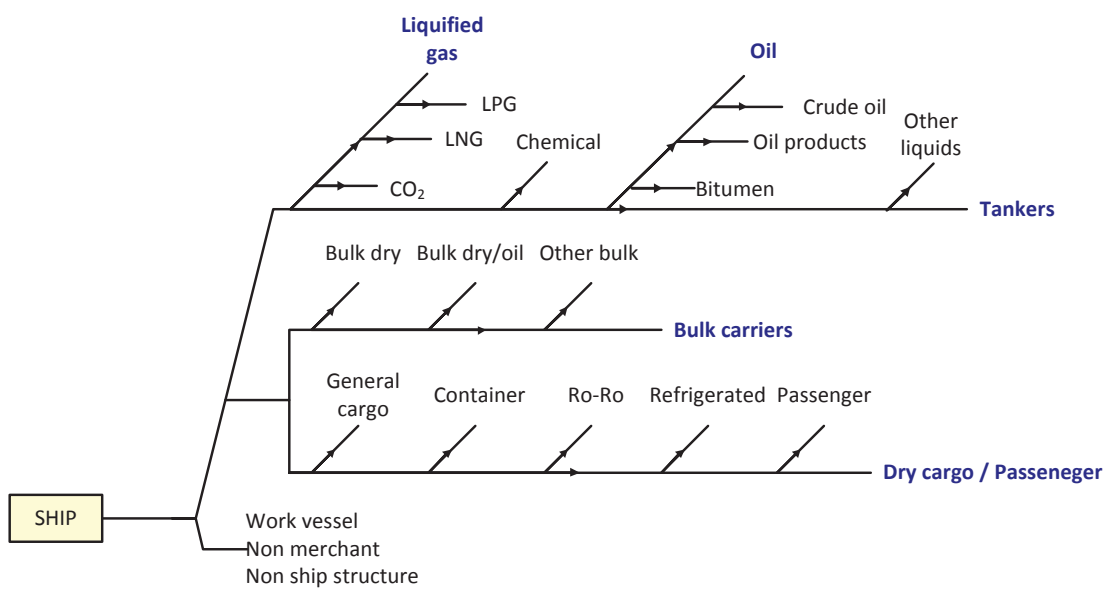

Fig. 1. A graphical representation of cargo carrying vessels applied for EEDI

For ship types not covered by the current EEDI formula, suitable formulas will be developed in the future. For each new ship; which falls into one of the listed categories, defined in IMO's project, the attained EEDI shall be considered as follows:

$$
\text { Attained } E E D I \leq \text { Required } E E D I=\left(1-\frac{X}{100}\right) R L V,
$$

where:

EEDI - [grams $\left.\mathrm{CO}_{2} / \mathrm{t}-\mathrm{NM}\right]$,

$X \quad-$ reduction factor [\%],

$R L V$ - reference line value [-].

The EEDI values are calculated from data on ship characteristics and performance accessible from primary sources - owner's data, but this will be supplanted by ship-sourced data as it becomes available. If the design of a ship pretend to maintain the required EEDI it shall be the most stringent (the lowest) required value. The regulation will require that a ship's EEDI be a certain percentage below a baseline value, which decline percentage will increase over time. Tab. 1 shows a proposal example of EEDI reduction program, expressed by set of reduction factors for typical container carriers [2].

Tab. 1. Reduction factors (in percentage) for the EEDI relative to the EEDI Reference Line

\begin{tabular}{|c|c|c|c|c|c|}
\hline \multirow{2}{*}{ Ship type } & Size & $\begin{array}{c}\text { Phase } 0 \\
\text { 1 Jan 2013- } \\
-31 \text { Dec 2014 }\end{array}$ & $\begin{array}{c}\text { Phase 1 } \\
\text { Jan 2015- }-31 \text { Dec 2019 }\end{array}$ & $\begin{array}{c}\text { Phase 2 } \\
\text { 1 Jan 2020- } \\
-31 \text { Dec 2024 }\end{array}$ & $\begin{array}{c}\text { Phase 3 } \\
\text { 1 Jan 2025 } \\
\text { and onwards }\end{array}$ \\
\hline $\begin{array}{c}\text { Container } \\
\text { carrier }\end{array}$ & 15000 DWT and above & 0 & 10 & 20 & 30 \\
\cline { 2 - 6 } & $1000-15000$ DWT & $\mathrm{n}^{* *}$ & $0-10^{*}$ & $0-20^{*}$ & $0-30^{*}$ \\
\hline
\end{tabular}

Reduction factor is to be linearly interpolated between the two values dependent upon vessel size. The lower value of the reduction factor is to be applied to the smaller ship size.

** n/a means that no required EEDI applies.

Moreover, the guidelines have been developed to assist with the preparation of Ship Energy Efficiency Management Plan (referred to as the "SEEMP") that are required by regulation of Annex VI of MARPOL 73/78 Convention [5]. The purpose of a SEEMP is to establish a mechanism to improve the energy efficiency of a ship's operation. Preferably, the ship-specific SEEMP is linked to a broader corporate energy management policy for the company that owns, 
operates, or controls the ship. Recognizing that there are a variety of options to improve ship's energy efficiency i.e. speed optimization, weather routing and hull maintenance, the specific implemented measures should be individually applied.

\section{The reference lines calculation for $E E D I$ use}

The reference lines are established for each ship type and are used for the determination of the required $E E D I$. A reference line is established as a curve representing an average index value fitted on a set of individual index values for a defined group of ships. Input data for the calculation of the reference lines is filtered through a process where data deviating more than two standard deviations from the regression line are discarded. The regression is then applied again to generate a corrected reference line. The IMO's MEPC has calculated EEDI reference lines, which denote the maximum allowable EEDI values that new ships constructed, can have, in order to be issued an International Energy Efficiency Certificate [4]. The reference line values - LRV of a container carrier shall be calculated as follows:

$$
R L V=174.2 \cdot b^{-0.201}
$$

where $b$ is a ship's DWT.

For all ship types, function parameters are determined from a regression analysis undertaken by plotting the calculated estimated index values against 100 per cent deadweight (100\% DWT). An estimated index value $(E I V)$ for each ship is calculated using the several constant assumptions, namely:

1. the carbon emission factor for all engines and dependent to fuel oil grade, i.e. $C_{F}=3.1144 \mathrm{~g}$ $\mathrm{CO}_{2} / \mathrm{g}$ fuel - for RM heavy fuel oil,

2. the specific fuel consumption for all main engines types, i.e. SFOC $=190 \mathrm{~g} / \mathrm{kWh}$,

3. the main engine power $-P_{M E}(i)$ is $75 \%$ of the total installed main power (MCR),

4. the specific fuel consumption for all auxiliary engines, i.e. SFOC $=215 \mathrm{~g} / \mathrm{kWh}$,

5. the auxiliary engine power $-P_{A E}(i)$ is $50 \%$ of the total installed auxiliary power.

For containerships, 70 percent of the deadweight $(70 \% D W T)$ is used as capacity for calculating the estimated index value for each containership as follows:

$$
E I V=3.1144 \cdot \frac{190 \cdot \sum_{i=1}^{N M E} p_{M E i}+215 \cdot p_{A E}}{70 \% D W T \cdot V_{r e f}},
$$

where $V_{\text {ref }}$ is measured ship speed, [knot].

\section{Energy Efficiency Design Index (EEDI)}

The attained EEDI shall be calculated for new ship, ship that has undergone a major conversion; and new or existing ship, which has undergone extensive that the ship is regarded as a newly constructed ship. The EEDI shall be specific to each ship and shall indicate the estimated performance of the ship in terms of energy efficiency, and be accompanied with technical file that contains process of calculation and results [6]. Survey and certification of the EEDI should be conducted on two stages: preliminary verification at the design stage, and final verification at the sea trial. The basic flow of the survey and certification process is presented in Fig. 2.

The EEDI Technical File contains a set of essential details, regarding the ship's hull and main propulsion. The principal particulars are deadweight $(D W T)$ or gross tonnage $(G T)$, the maximum continuous rating $(M C R)$ of the main and auxiliary engines, the ship speed $\left(V_{r e f}\right)$, type of the fuel, the specific fuel oil consumption $(S F O C)$ of the main engine and auxiliary engines and the electric power data. The ship's main propulsion power curve is estimated at design stage for preliminary 


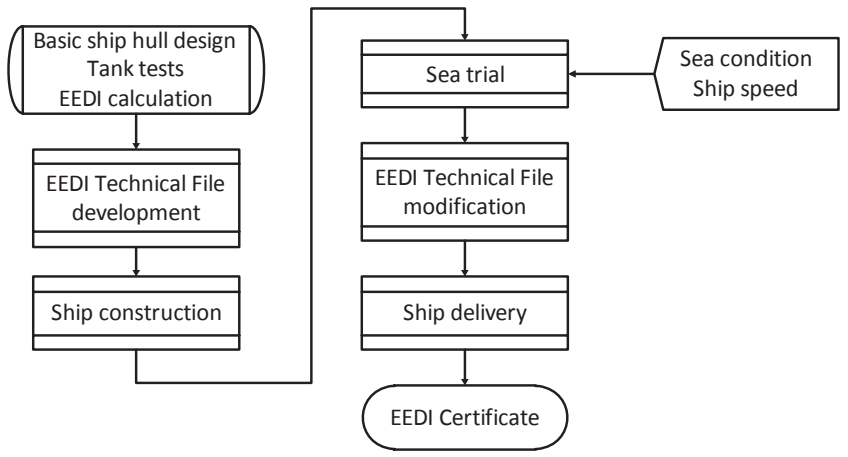

Fig. 2. The EEDI flow of survey and certification process

evaluation and when ship is delivered, sea trial test is used for final approval and assessment. The realistic power curve needs to be based on the measured ship speed and the measured output of the main engine at sea trial, which shows Fig. 3.

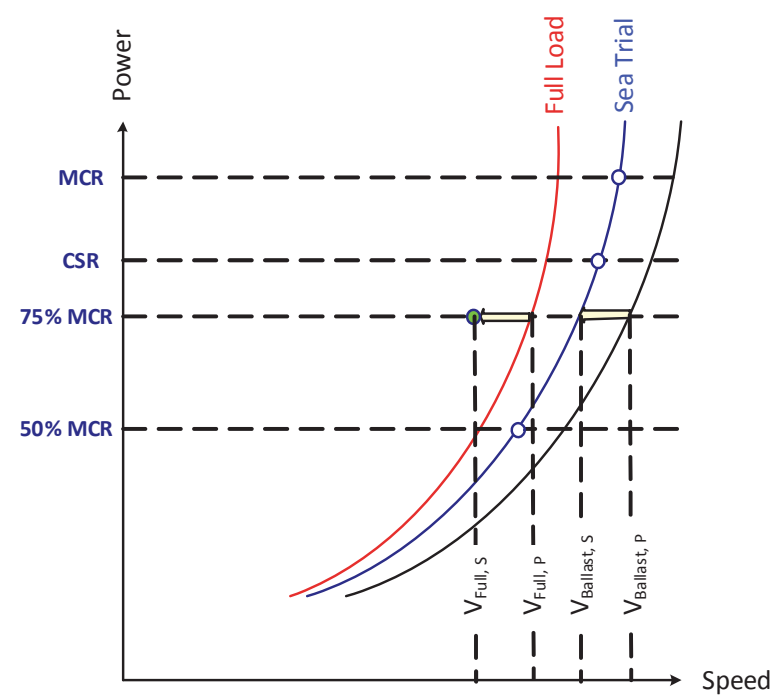

Fig. 3. The ship's power curve development

The EEDI is a measure of ships energy efficiency $(\mathrm{g} / \mathrm{t} \cdot \mathrm{nm})$ and calculated by the following formula:

$$
\begin{gathered}
E E D I=\frac{\left(\prod_{j=1}^{n} f_{i}\right)\left(\sum_{i=1}^{n M E} P_{M E(i)} \cdot C_{F M E(i)} \cdot S F O C_{M E(i)}\right)+\left(P_{A E} \cdot C_{F A E} \cdot S F O C_{A E^{*}}\right)}{f_{i} \cdot f_{c} \cdot \text { Capacity } \cdot f_{w} \cdot V_{\text {ref }}}+ \\
+\frac{\left[\left(\prod_{j=1}^{n} f_{i} \cdot \sum_{i=1}^{n P T I} P_{P T I(i)}-\sum_{i=1}^{n e f f} f_{\text {eff }(i)} \cdot P_{A E e f f(i)}\right) C_{F A E} \cdot S F O C_{A E}\right]-\left(\sum_{i=1}^{n e f f} f_{\text {eff }(i)} \cdot P_{\text {eff }(i)} \cdot C_{F M E} \cdot S F O C_{M E * *}\right)}{f_{i} \cdot f_{c} \cdot \text { Capacity } \cdot f_{w} \cdot V_{\text {ref }}},
\end{gathered}
$$

and if electric shaft motor installed, propulsion power at $V_{\text {ref }}$ is:

$$
\sum P_{M E(i)}+\sum P_{P T I(i), \text { Shaft }},
$$

where:

$$
\sum P_{P T I(i), \text { Shaft }}=\sum\left(P_{P T I(i)} \cdot \eta_{P T I(i)}\right) \cdot \eta_{\overline{G e n}},
$$


and:

$\eta_{P T I(i)}$ - efficiency of electric motors,

$\eta_{\overline{G e n}}$ - weighted average efficiency of generators.

In case where shaft generator is installed, $P_{P T O(i)}$ is $75 \%$ of the rated electrical output power of shaft generator. The deduction of $P_{M E(i)}$ is calculated as:

$$
P_{M E(i)}=0.75 \cdot\left(P_{M E, M C R(i)}-P_{P T O(i)}\right) .
$$

The adequate guidance for $P_{M E(i)}$ estimation gives Fig. 4.

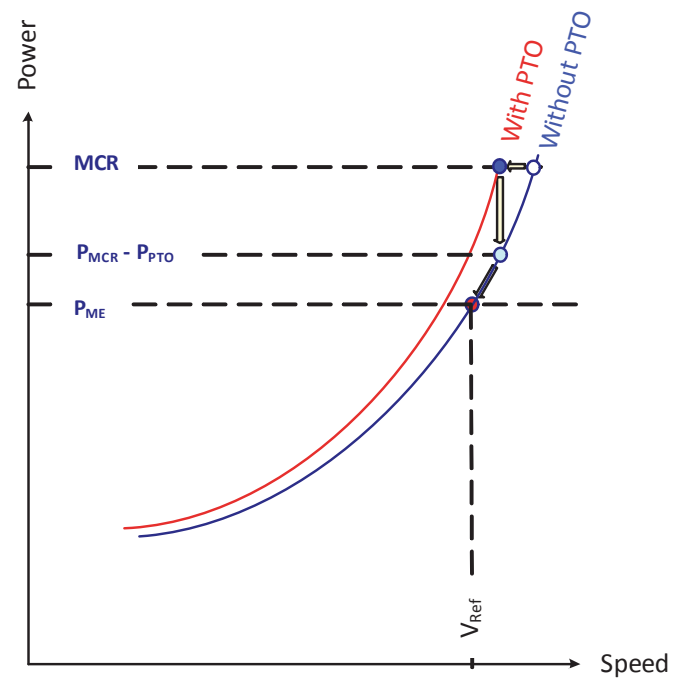

Fig. 4. Main propulsion engine effective power evaluation with Power Take Off arrangement

The ship's electric power is usually generated by: several diesel engine driven synchronous generators and optionally turbine driven generator or propeller shaft driven synchronous generator, with power take in facility emergency generator. The electricity is distributed via main switchboard. Bus bar powers all the electrical main consumers i.e. bow thrusters, heavy deck machinery, and engine room systems. The simplified marine power plant layout presents Fig. 5.

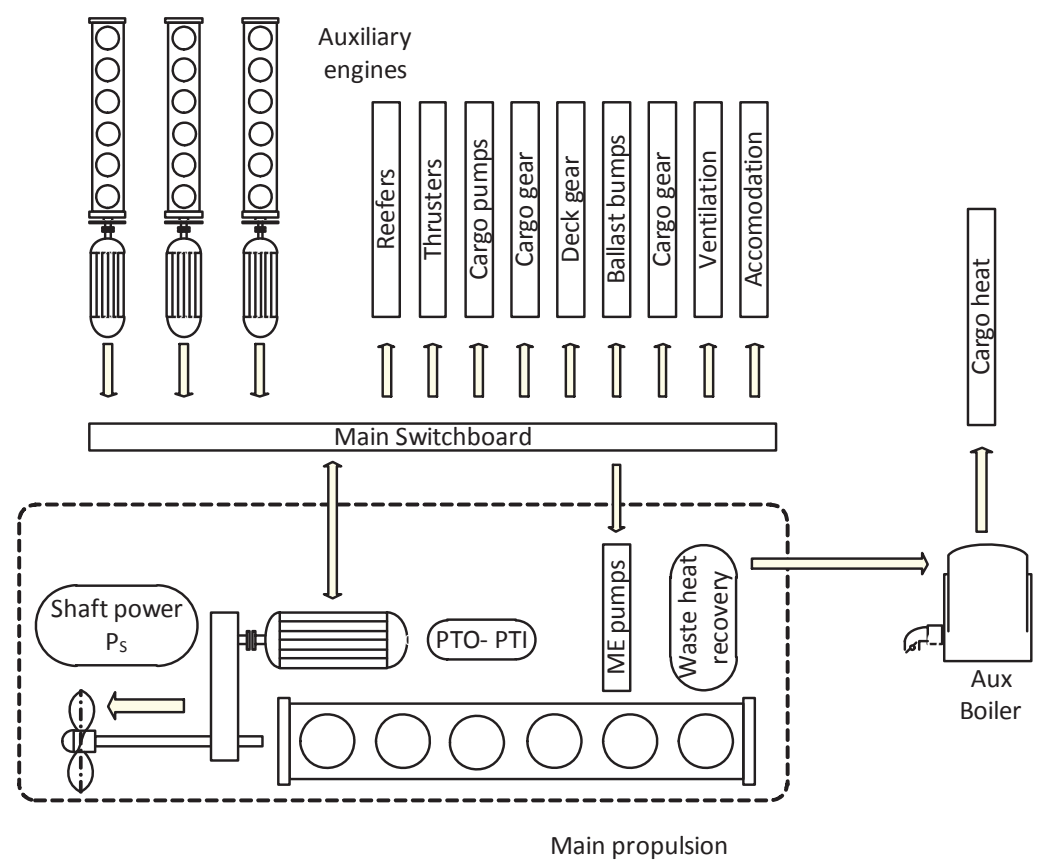

Fig. 5. Marine power plant layout 
Each electric generator is driven by turbocharged, four-stroke, auxiliary diesel engine which is equipped with separate, integrated systems for cooling water, fuel oil and lubrication oil. The power from the shaft of the main engine drives the electric shaft generator via a gear and a clutch. The shaft generator can supply the ship's network with electrical energy (Power Take Off mode) when main engine is running. The shaft generator is designed for continuous parallel operation with conventional auxiliary generators and optionally exhausts gas turbo-generator sets. The shaft generator can be used as a motor in Power Take In mode. This enables excess available electrical power to be used to supplement the main engine to give greater shaft output.

In PTI mode, either the motor can use the available electrical capacity or the maximum consumption can be manually selected. Auxiliary effective power $\left(P_{A E}\right)$ is the required auxiliary engine power to supply normal maximum sea load, including necessary power for propulsion machinery systems and accommodation, e.g. main engine pumps, navigational systems and equipment and living on board, but excluding the power not for propulsion machinery systems, e.g. thrusters, cargo pumps, cargo gear, ballast pumps, maintaining cargo, e.g. reefers and cargo hold fans, in the condition where the ship engaged in voyage at the speed $\left(V_{r e f}\right)$. For ships with a main engine, power of $10000 \mathrm{~kW}$ or above, $P_{A E}$ is defined as:

$$
\begin{gathered}
P_{A E}=0.025 \cdot\left(\sum_{i=1}^{n M E} P_{M E, M C R}+\frac{1}{0.75} \sum_{i=1}^{n P T I} P_{P T I(i)}\right)+250, \\
P_{A E}=0.05 \cdot\left(\sum_{i=1}^{n M E} P_{M E, M C R}+\frac{1}{0.75} \sum_{i=1}^{n P T I} P_{P T I(i)}\right) .
\end{gathered}
$$

\section{The EEDI assessment for container carrier}

The sea service trials carried out on board the container vessel, aimed an evaluating the ships' main propulsion engine performance. During the sea trial, several important characteristics were investigated, supported by the main engine rotational speed and torque, which has been measured in order to obtain realistic engine developed power - in accordance to the ISO 3046 standard. The ships and main propulsion particulars presented in Tab. 2. Many variables affect the performance of a ship's propulsion at sea, so the acceptance sea trial gives practical basis to create a propulsion specification. The ship sea trials are conducted at the end of ship construction. Therefore, measured ship speed and shaft power must be corrected. Important parameters for a main propulsion engine are the rating figures, usually stated as: continuous service rating (CSR) and maximum continuous rating (MCR).

Tab. 2. The vessel and main engine specifications

\begin{tabular}{|c|l|c|}
\hline No & \multicolumn{2}{|c|}{ Description } \\
\hline 1 & Class & Container vessel \\
\hline 2 & Length over all & $178.57 \mathrm{~m}$ \\
\hline 3 & Breadth moulded & $27.70 \mathrm{~m}$ \\
\hline 4 & Draught - design, loaded & $10.87 \mathrm{~m} / 10.64 \mathrm{~m}$ \\
\hline 5 & Deadweight & $22300 \mathrm{TDW}$ \\
\hline 6 & Container intake & 1856 TEU \\
\hline 7 & Main engine & MAN B\&W 6L70ME-C \\
\hline
\end{tabular}

The determined measured sets data were used for main propulsion service area designation and comparison with nominal engine performance that was made during the acceptance: shop trial and sea trial, after the ship construction completion - see Fig. 6 (right). The applicable real-valued functions comparison is presented in Fig. 6 (left). Basically, propulsion service operation area is 
placed between the curve of a ship sea trial - light condition and the engine nominal curve. However, when heavy weather condition occurred, main engine propulsion load could be shifted beyond the nominal curve, hence engine overload encountered. Determination of the average propulsion power curve was primarily task of ship's sea trial survey. An additional aspect of the main propulsion performance operational testing was determined by fuel oil consumption matrix.
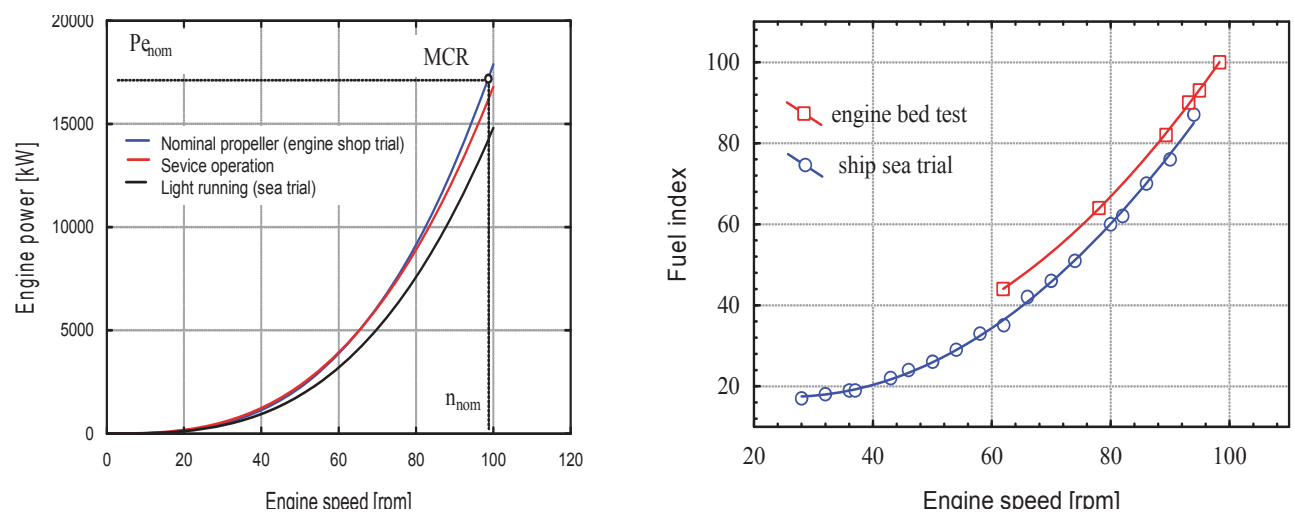

Fig. 6. Ship main propulsion power curve evaluation based on service and construction performance

Determination of specific indicators related to $\mathrm{CO}_{2}$ emissions and IMO procedure is based on the mechanical factors of ship main and auxiliary propulsion engines. In this case, the main propulsion system and auxiliary engines are represented by modern units with up-to-date design and excellent energy performance. Basic engines specifications are shown in the Tab. 3.

Tab. 3. The main and auxiliary engines specifications for attained EEDI

\begin{tabular}{|c|c|c|c|c|c|}
\hline \multirow{2}{*}{\multicolumn{2}{|c|}{ Ship propulsion }} & \multicolumn{2}{|c|}{ Main } & \multicolumn{2}{|c|}{ Auxiliary } \\
\hline & & \multicolumn{2}{|c|}{ Direct, fixed pitch propeller } & \multicolumn{2}{|c|}{ Diesel engine generator } \\
\hline \multicolumn{2}{|c|}{ Engine } & \multicolumn{2}{|c|}{ MAN B\&W 6L70ME-C } & \multicolumn{2}{|c|}{ YANMAR, 6N21AL-EV } \\
\hline \multirow{2}{*}{ MCR } & Power & $\mathrm{kW}$ & 16980 & $\mathrm{~kW}$ & 970 \\
\hline & Speed & $\mathrm{r} / \mathrm{min}$ & 98.3 & $\mathrm{r} / \mathrm{min}$ & 900 \\
\hline \multicolumn{2}{|c|}{ SFOC at specified engine load* } & $\mathrm{g} / \mathrm{kWh}$ & 183.5 & $\mathrm{~g} / \mathrm{kWh}$ & 298.0 \\
\hline \multicolumn{2}{|c|}{ Fuel type } & \multicolumn{2}{|c|}{ RMH 380} & \multicolumn{2}{|c|}{ RMH 380} \\
\hline
\end{tabular}

*Main engine $-75 \%$ of MCR, Auxiliary engine $-50 \%$ of MCR

Assuming designated ship's power characteristics, the composite dependence which includes main propulsion developed power, propeller speed and the vessel speed, calculations algorithm developed for EEDI and EIV factors[7]. Determination of ship power curves has not been analyzed according to IMO procedure, since it is based entirely on the experimental measurement results that were carried out under service operating conditions. Adequately, fuel consumption is based on a set of direct measurements and calculations to standard ISO conditions. Main engine fuel oil system is designed for residual grade, and it would be used for auxiliary engines as well. The results of the calculation of the EEDI for the ship in question are included in Tab. 4.

Tab. 4. The main and auxiliary engines specifications for attained EEDI

\begin{tabular}{|c|c|c|c|}
\hline Ship propulsion & \multicolumn{2}{|c|}{ Main } & \multicolumn{2}{c|}{ Auxiliary } \\
\hline $\mathrm{P}_{\mathrm{MEi}} / \mathrm{P}_{\mathrm{AE}}$ & $\mathrm{kW}$ & $\mathrm{kW}$ & 970 \\
\hline $\mathrm{CF}_{\mathrm{ME}} / \mathrm{CF}_{\mathrm{AE}}$ & \multicolumn{2}{|c|}{3.1144} & 3.1144 \\
\hline Attained EEDI & $\mathrm{g} \mathrm{CO}_{2} / \mathrm{t} \cdot \mathrm{nm}$ & 35.10 \\
\hline Estimated Index Value -EIV & $\mathrm{g} \mathrm{CO}_{2} / \mathrm{t} \cdot \mathrm{nm}$ & & 35.14 \\
\hline EIV - measured & $\mathrm{g} \mathrm{CO}_{2} / \mathrm{t} \cdot \mathrm{nm}$ & & 36.94 \\
\hline Reference Line Value - RLV & $\mathrm{g} \mathrm{CO}_{2} / \mathrm{t} \cdot \mathrm{nm}$ & \multicolumn{3}{|c|}{23.53} \\
\hline
\end{tabular}


The ship does not have additional equipment as: shaft generators, which allow PTO or PTI, functioning and finally, waste heat energy recovery systems. Then, for EEDI specific value calculation, the proper correction factors were not included. Also, no correction factors applied due to weather deterioration and ice-class hull.

\section{Conclusions}

A $\mathrm{CO}_{2}$ design index has been in development within the IMO. The index is currently commonly known as the Energy Efficiency Design Index (EEDI). Once approved, it will in theory reduce $\mathrm{CO}_{2}$-emissions from new ships in the future. It will first apply to conventional vessels.

Container carriers are designed for carriage standard transportation units. The design criteria for these ships are very diverse. Typically, container carriers are dimensioned by available cargo volumes, and when these ships operate as part of a logistics chain, schedules are usually very tight. Then, design speed of the vessel is determined by the sailing schedule on a certain route. As the ships design criteria, schedules and operation areas vary, there is a large scatter of design speeds and installed engine powers within the same size groups. Data to be used for the ship in this study is mainly based on the service experimental sea trial. Currently, such vessel is benchmarked against IMO's limitations and reference line value - RLV is used for comparison. The primary comparison with attained $E E D I$ and $E I V$ shows considerably difference and $49 \%$ higher value than recommended.

The main goal of the EEDI is to prevent the design of the most inefficient ships by setting certain energy efficiency requirements. In practice, this will result in a reduction of installed engine power, which will reduce the service speeds of the majority of vessels [8]. However, with container vessels, the power is mainly used for making journeys in the allocated time frame. EEDI is intended to be a design index, and thus the main emphasis of it is to design of the vessels. However, the design of the vessel influences directly also the operation of the vessels.

The impact on vessel design could be that theatrically large superstructures are designed in order to increase the gross tonnage of the vessel in order to decrease the attained EEDI value. The future reduction targets will cut down the speeds of container vessels even further, as there are no other realistic technical solutions to meet the targets of $20-30 \%$ emission reductions by the year 2025 .

\section{References}

[1] Northern Ireland Environmental Agency, Measuring the effectiveness of Environmental Management Systems, Phase 1: Desktop Report, www.ni-environment.gov.uk, June 2009.

[2] IMO, Amendments to the Annex of the Protocol of 1997 to Amend the International Convention for the Prevention of Pollution from Ships, 1973, Annex 19, Resolution Mepc.203(62), Adopted on 15 July 2011.

[3] Deltamarin LTD, Study on tests and trials of the Energy Efficiency Design Index as developed by the IMO, Applicability and Refinement of the EEDI for Ro-Ro and Ro-Pax Vessels, Report for Project 6543, 2011.

[4] IMO, Guidelines for Calculation of Reference Lines for Use with the Energy Efficiency Design Index (EEDI), Mepc 63/WP.9, Annex 4, Adopted on March 2012.

[5] IMO, Draft 2012 Guidelines for the Development of a Ship Energy Efficiency Management Plan (SEEMP), MEPC 63/4/11.

[6] IMO, Guidelines on the Method of Calculation of the Attained Energy Efficiency Design Index (EEDI) for New Ships, MEPC 63/WP.9, MEPC 63/WP.9.

[7] Bazari, Z., Longva, T., Assessment of IMO Mandated Energy Efficiency Measures for International Shipping, Estimated $\mathrm{Co}_{2}$ Emissions Reduction from Introduction of Mandatory Technical and Operational Energy Efficiency Measures for Ships, Project Final Report, 31.10. 2011.

[8] Devanney, J., EEDI - A Case Study in Indirect Regulation of $\mathrm{CO}_{2}$ Pollution, Center for Tankship Excellence, Version: 1.11, www.gnu.org, 23.12.2010. 